Western University Scholarship@Western

Philosophy Publications

Philosophy Department

Spring 2017

\title{
The Medical Nonnecessity of In Vitro Fertilization
}

Carolyn McLeod

The University of Western Ontario, cmcleod2@uwo.ca

Follow this and additional works at: https://ir.lib.uwo.ca/philosophypub

Part of the Philosophy Commons

Citation of this paper:

McLeod, Carolyn, "The Medical Nonnecessity of In Vitro Fertilization" (2017). Philosophy Publications. 479.

https://ir.lib.uwo.ca/philosophypub/479 


\title{
THE MEDICAL NONNECESSITY OF IN VITRO FERTILIZATION CAROLYN MCLEOD
}

\begin{abstract}
Debate has raged in Canada recently over whether in vitro fertilization (IVF) should be funded through public health insurance. Such a move would require that the provinces classify IVF as a medically necessary service. In this paper, I defend the position I have taken publiclyespecially in Ontario, my own province - that IVF is not medically necessary. I contend that, by funding IVF on grounds of medical necessity, governments like Ontario's violate their commitments to equality and fairness, and cause harm. They do the last by suggesting that the lives of people who forgo procreation, and perhaps have children in other ways (e.g., through adoption), will be stunted.
\end{abstract}

Keywords: In vitro fertilization, medical necessity, public funding, adoption, fertility treatment

\section{Introduction}

Whether in vitro fertilization (IVF) is medically necessary (or essential) determines, in many jurisdictions, whether it ought to be funded through public health insurance. This is certainly the case in Canada, where the Canada Health Act (1985) requires that provinces pay for all medically necessary health care services (Kaposy 2009). Debate raged recently in Ontario, my own province, over whether IVF should be deemed medically necessary and therefore covered under Ontario's Health Insurance Plan (OHIP). Advocates for public funding insisted 
that Ontario, along with most other provinces in Canada, were behind the times in not having such funding, given how many governments around the world, including most European ones, cover the costs of multiple cycles of IVF (see, e.g., Canadian Fertility and Andrology Society 2014).

By contrast, others, including me, argued that IVF should not be funded under OHIP (see, e.g., McLeod and Botterell 2014). ${ }^{1}$ In this paper, I explain in detail why I took this stand. To be clear about my position, it is not that IVF is always medically inappropriate. It is appropriate for people who strongly desire to have biological children but who cannot have them without medical assistance. However, it is not reasonable for a government like Ontario's to support the preference that many people have for biological children by funding IVF on grounds of medical necessity. (Whether such a government should fund IVF on other grounds, assuming that's possible, is not an issue on which I take a position in this paper. See section 3.c. below. I also do not take a stand on whether the government should fund forms of fertility treatment other than IVF on grounds of medical necessity. See section 3.b. below. $)^{2}$ As is evident in what follows, my argument is relevant to governments that are similar to Ontario's in being liberal democratic and in governing over communities in which people generally have some freedom not to desire to have biological children; they would not be subject to abuse, serious social ostracism, or the like if they rejected this desire - as they would unfortunately be if they lived in other parts of the world (McLeod and Ponesse 2008). For simplicity, I refer simply to "the government," by which I mean a government of this sort.

Why do I say that IVF should not be classified as a medically necessary service by the government? My reasons, in brief, are the following. Decisions about which treatments are medically necessary cannot be separated from decisions about how important it is that people 
have the capacity that the treatment seeks to restore or give to patients. In the case of IVF, this capacity normally is procreation. ${ }^{3}$ IVF is expensive, carries risks, and is stressful. In my view, the government should not consider procreation to be so important that it is willing to fund IVF on grounds of medical necessity. Doing so would involve assuming that becoming a parent through procreation is superior to becoming a parent in other ways (e.g., through adoption) or to choosing a life without children. The government cannot endorse such a view without violating its commitments to equality and fairness, and without harming people, including children waiting to be adopted.

This paper has two main parts. In the first part, I clarify why I believe the following are interlocking questions: (1) Is IVF medically necessary? (2) To what extent do we value people's ability to conceive and bear children? Here and elsewhere, I rely on a common sense definition of a medically necessary service: that such a "service is one that a patient needs in order to avoid a negative health consequence" (Charles et al. 1997, 365). ${ }^{4}$ In claiming that we cannot identify needs of this sort, or establish their importance, without deciding how much we value certain physiological or psychological capacities, I appeal to literature in the philosophy of medicine on health and disease.

In the second part, I explain why, in deeming IVF medically necessary, the government would be valuing procreation at a high level, and why this level is simply too high because it does not allow the government to appreciate other ways of becoming a parent, such as adopting a child, or the potential value of forgoing parenthood altogether. Of particular relevance here is the effort and expense that goes into making IVF work. One has to be very committed to bearing children to be willing to proceed with IVF. In discussing this specific point and the more general point about how much the government should value procreation (compared, e.g., with adoption), 
I draw on literature in philosophy, bioethics, and sociology on IVF, procreation, and adoption. I also appeal to my personal experience with infertility, being an IVF patient and an adoptive mother. My partner and I did two cycles of intrauterine insemination and one cycle of IVF before turning to adoption to become parents. At around the same time, I was witness to my sister's struggle with infertility, and to the joy she felt in giving birth to two children. This personal perspective complements the research I do on infertility and adoption. Both give me insight into what it is like to be infertile, to undergo IVF, and to adopt a child.

\section{Interlocking questions}

Let me begin with a discussion not about IVF but about how to understand medical necessity. I have already said that we cannot determine what is medically necessary without reflecting on which capacities we value. I have also appealed to the common sense idea that medical necessity is connected with health needs. What our values are shape what these needs are, according to many theories of health in the philosophy of medicine (Ereshefsky 2009). Nonetheless, there are prominent theories of health—naturalist theories—according to which this claim about values is false. In addition, one could use such a theory to describe what is medically necessary without making reference to what we value. In this section, I show that such an argument will not work. In particular, it fails to establish that questions about medical necessity and about what we value are separate. I conclude that these questions are indeed interlocking. Whether IVF is medically necessary therefore depends on how much value the government places, or is willing to place, on procreation.

Before turning to the view that I reject, let me clarify briefly my own view about medical necessity. To reiterate, I believe that we would not identify a certain service as medically 
necessary unless we valued the capacity that the service would restore, if only temporarily. We would also have to value it to the degree that the service demands, given, for example, how invasive or expensive the service is. Only then would we say that the relevant service satisfies a health need, and only if we valued the relevant capacity would we say that it is important to our health. With this last point, I am relying on a view about health according to which values play an important role in determining who or what is healthy (and who or what is diseased) (Ereshefsky 2009, 222). ${ }^{5}$ My reasons for interpreting the term "health" in this way should be clear from my discussion below about theories of health — naturalist theories - that describe it as value neutral.

People who are naturalists about health might claim that judgments about medical necessity are not value judgments. The most influential proponent of naturalism is Christopher Boorse (1975; Ereshefsky 2009, 222-23). For Boorse, health is the absence of disease, and disease is an impairment of species-typical normal functioning. ${ }^{6}$ Moreover, human beings have a natural design and are healthy or diseased depending on whether we function in a way that conforms to this design (57). The design includes functions that contribute to the goals we have as biological organisms: to survive and reproduce. The natural functions of components of us are their "species-typical contributions" to our biological fitness (57). To be clear, "natural" and "normal," in this theory, do not mean desirable (57). Certain states are healthy or diseased independently of whether people desire them. A human being is diseased when she or he exhibits some biological dysfunction, regardless of whether people value the relevant form of functioning.

One could certainly draw on Boorse's theory to try to show that IVF and other fertility treatments are medically necessary, and do so without discussing how desirable procreation is for 
us. The argument would proceed as follows. Infertility is a form of procreative dysfunction. ${ }^{7}$ Infertility is therefore a disease, at least for people in certain age groups (see note 6). To avoid or remedy this disease, some patients require fertility treatments such as IVF. Consequently, these treatments are medically necessary. Here, "medical necessity" refers simply to what people need to attain species-typical normal functioning, and biology alone determines such need, rather than biology and values. ${ }^{8}$ No value judgment is required.

Such an approach, however, is seriously problematic. Some of its problems interestingly have nothing to do with how it interprets "health" and "disease." Let me discuss two such concerns. First, since the argument deems medically necessary fertility services used only by people who have an underlying disease (i.e., mainly heterosexual couples) rather than people who simply have a desire to have children that they cannot satisfy without assistance from others (i.e., mainly single people and homosexual couples), it would appear to condone a system of unequal access to these services, one in which only heterosexual couples can get publicly funded treatment. ${ }^{9}$ Second, the argument implies that all treatments for disease are medically necessary. However, there are treatments and there are treatments, and not all of them are medically necessary. ${ }^{10}$ Some are better than others (e.g., purely on grounds of cost), and, for some, there are nonmedical alternatives. To illustrate the latter point: improving the social environments of people who have physical disabilities by making these environments more accessible to them can be a nonmedical alternative to correcting, or trying to correct, their medical problems. It can be a better alternative moreover depending on the nature of the medical fix (e.g., how invasive it is) and of the nonmedical fix (e.g., how feasible it is). Similarly, adoption is a nonmedical alternative to fertility treatment, and can be an equal, if not a better, alternative depending on the 
nature of the recommended medical treatment for infertility, as well as how functional and ethical available systems of adoption are.

The above approach to understanding medical necessity is also problematic, however, because of how it interprets "health" and "disease." There are concerns about whether Boorse's theory can explain disagreements we have over what counts as a disease ${ }^{11}$ and also whether it is value-free in its use of the terms "natural" and "normal" (Ereshefsky 2009, 222-23; Daniels $1985,30)$. But let me focus on a different problem, one that assumes that our understanding of medical necessity should conform to medical practice and questions whether Boorse's theory satisfies this criterion. There are two issues here. The first is that "medical practice unquestionably presupposes the value of health," as Boorse himself admits (60), ${ }^{12}$ whereas his theory describes health as value neutral. In medical practice, that is, biological functions that count in assessments of health and disease are those, and only those, that are deemed important or desirable. (Abnormal functioning that is considered unimportant does not count as a health failure.) The second issue is that, unlike the theory, medical practice does not treat human beings merely as biological organisms. Patients are understood as having multiple goals, including goals that can conflict with biological fitness (Ereshefsky 2009, 223). For example, a patient can reasonably request to be sterile because of career goals she has. Thus, again assuming that our understanding of medical necessity should conform to medical practice, it cannot be defined in terms of Boorse's theory of health, and more generally, cannot treat health as though it were value neutral.

To conclude this section: any attempt through philosophical argument to divorce questions about medical necessity from those about what we value is bound to fail. Such an argument would have to appeal to a conception of health that cannot explain the importance we 
associate with certain health needs when we say that satisfying them is medically necessary. In so doing, we do not conceive of health as value neutral. Rather, we make a judgment about what value health has, or what value specific capacities have that may contribute to our health. By extension, in deciding whether a particular intervention is medically necessary, we must agree on the value of the capacity that the intervention might restore, if only temporarily. Assuming that is correct, let us turn now to procreation.

\section{Valuing procreation}

Compared to many other capacities that medical treatment might restore or provide, the value that procreation has for us is obscure. While few people would question the importance of being able to breathe easily, for example, many would dispute the value of procreation. For some people, the ability to procreate (i.e., their fertility) is an impediment to them leading a good life, which for them is a life without children. At the opposite extreme are the many people for whom infertility is a serious barrier to happiness (McMillan 2001, 12). And, in the middle, are those who find infertility disappointing, but not at all tragic (Uniacke 1987, 244). ${ }^{13}$

It is common to assume that everyone experiences infertility in the same way as the second group above: that is, as a serious barrier to happiness. Yet, most of the studies used to support such a claim focus on people who seek or have sought treatment for infertility (e.g., Freeman et al. 1985; Domar et al. 1993; Chen et al. 2004). And there is a problem with generalizing from this group to everyone who is infertile. In his widely cited paper about infertility and psychological distress, Arthur Greil (1997) notes that, by focusing on "clinic samples" (as most of the literature does in this area), one lets "a select group of the infertile, who are almost certainly not representative of the infertile population as a whole, speak for the whole 
group" (1699). Thus, according to Greil, we cannot conclude, because some or many patients of fertility clinics experience extreme anxiety about their infertility, that infertility generally is a source of immense unhappiness for people.

Given that people's opinions clearly do differ about the value of procreation, it is not obvious what value procreation has for us. My question is whether the government should ascribe such a high value to procreation that it categorizes IVF as a medically necessary service. I believe that the answer is no. Let me proceed by explaining first the nature of IVF, second how much one would have to value procreation in order to deem IVF medically necessary, and third why the government valuing it this much would, in my opinion, be inappropriate and wrong.

\section{a. In vitro fertilization}

An important background issue for this paper concerns the nature of IVF. In describing IVF, I will draw heavily, though not exclusively, from a report produced by the Ontario Ministry of Children and Youth Services' Expert Panel on Infertility and Adoption (2009; hereafter, "the Expert Panel" and "the Report"), a panel which, to be clear, advocated in favor of public funding for IVF. For the bare facts about the process of IVF, see the Report (98-99). This fertility intervention enables some people to bear a child; however, it is also often unsuccessful, it is expensive, it carries risks (in addition to those associated with an increased chance of having a multiple birth), and it is stressful. I defer to the Canadian Fertility and Andrology Society (2014) on the matter of success rates (i.e., in Canada),${ }^{14}$ and to the Report on matters of cost and risk (see 109-10 on cost, and 101-12 on risks).

Let me discuss briefly why IVF is stressful psychologically. The sources of stress for IVF patients are potentially very numerous. Cost is one source, and admittedly a big one, for many people; but there are other sources as well. For example, IVF is time consuming, particularly for 
women, because of the frequent blood tests and ultrasounds (Report 2009, 98). The time commitment involved with even one cycle of IVF is substantial and can pose serious difficulties for women who have paying jobs. Many women experience significant physical discomfort from the treatments (Suthersan et al. 2011), which can be stressful. There are also the "ups and downs" of treatment, which are mentioned in the Report (121). The treatment can go well one day, badly the next, and even worse the next—or actually better (!). ${ }^{15}$ Finally, there is the stigma associated with being infertile, which can be heightened while undergoing IVF. The Report often refers to the stigma of infertility, but says little about its nature. It suggests that this problem exists because people assume that infertility is somehow voluntary (134), which would mean that people who are infertile are responsible for it. Indeed, many women, in particular, blame themselves for infertility, even when it is unexplained (McLeod and Ponesse 2008). They do so, in part, because others tell them that if they just relaxed, they would get pregnant. The Report neglects to mention how much stronger these social messages can become during IVF treatment. Everything is timed so perfectly. How could it not work? If it fails, it must be the patient's fault.

There are studies showing that IVF is stressful enough that many patients stop the treatment even when they have been relieved of the burden of financing it. One such report states that the "most common reason that patients drop out of IVF treatment, even when it is covered by medical insurance, is psychological distress" (Cousineau and Domar 2007, 304). The authors claim, more precisely, that, in a number of surveys done in countries where people are insured for IVF treatment, "the psychological burden of the procedures appeared to be the major reason for drop-out" (300). Among these studies is a "large Swedish [one] of 974 couples," which "reported that two thirds (65\%) did not complete the three IVF cycles which were covered under their health plan"; and a "retrospective study of over 2000 German patients," which "found that, 
despite the fact that these patients were covered by insurance for four cycles, the drop-out rate of non-pregnant patients was $40 \%$ after the first cycle ..." (300). In short, IVF can be very burdensome psychologically even when patients do not pay for it themselves.

The nature of IVF explains why one would have to place substantial value on procreation in order to accept the medical necessity of it. But so does the presence of alternatives to IVF. Let me turn to these topics now.

\section{b. Valuing procreation: how much?}

In saying that IVF is medically necessary, one implies that the inability to procreate is a serious health condition comparable to other conditions that most patients would go to great lengths medically to try to fix. The opportunity to attempt to bypass the condition through IVF is worth the months of medical appointments, injections, difficult scheduling, emotional ups and downs, and so on. Procreation must be worth this much if IVF is indeed medically necessary. But procreation also has to be more valuable than the alternatives to IVF, including adoption, which satisfies what is surely the most important goal of procreation: having children. ${ }^{16}$ That is, for IVF to be medically necessary, procreation has to be superior to adoption as a way of forming a family with children, and also superior to having no children. Procreation has to be so valuable that it is worth not only undergoing the effort and incurring the risks involved in IVF, but also forgoing the alternatives. ${ }^{16}$ Some individuals indeed may value procreation this much; however, the issue here is whether the government should do so.

Some might object that in deeming IVF medically necessary, the government would not be valuing procreation over adoption, but rather would simply be valuing parenting. The reason is that for many people who cannot have children on their own, becoming a parent is best achieved through IVF. Adoption is not, in fact, a good alternative to IVF, specifically because of 
how difficult it tends to be to adopt a child. Thus, without access to IVF, these people really have no good options for becoming parents. One problem with this objection is that it is questionable whether it is generally harder to adopt a child than to undergo IVF. ${ }^{18} \mathrm{~A}$ further problem is that adoption need not be as difficult as it currently is in many places. For example, the Expert Panel (2009) recommended in the Report various changes that would make adoption—particularly, public domestic adoption - a better, easier option for many people in Ontario. Hence, comparing IVF with the status quo on adoption is inappropriate, at least in Ontario where the status quo on adoption is in need of serious repair (Cohn 2015b) $\cdot{ }^{19}$ Moreover, making such a comparison while simultaneously arguing that the status quo on IVF needs to change (i.e., so that IVF becomes publicly funded) is simply unreasonable. Since the objection we are now considering commits such an error, it cannot refute my claim that to endorse the medical necessity of IVF is to promote procreation over adoption.

As an aside, consider that the process of adoption may always be more difficult than pursuing fertility treatments that are less invasive or intensive than IVF (e.g., surgery to fix a malformed uterus or laparoscopy to treat endometriosis), and thus perhaps the government should fund them at least on grounds of medical necessity. To do so, it would not need to value procreation as much as it would to fund IVF (assuming also that these treatments are less expensive). Without committing myself to any particular position on this matter, let me say that, given how I have understood medical necessity—in particular the connection I've drawn between medical necessity and what we value - the government could consistently classify as medically necessary these less invasive and expensive fertility treatments without doing the same for IVF. Doing so would suggest that it values procreation only to the degree implied in funding these particular treatments. 


\section{c. Valuing procreation: too much}

Thus far, I have claimed that, in order to classify IVF as a medically necessary service, procreation must be highly valued, and valued more than other ways of forming a family with children and also more than having a life without children. Let us now discuss whether the government should value procreation to this extent. There are serious problems with it doing so, in my opinion, including problems having to do with equality, fairness, and harm.

\section{Equality}

The issue of equality is controversial. Some argue that the status quo on IVF in North America, according to which IVF is not publicly funded, actually exacerbates inequality by allowing only the rich to access this service (e.g., Nisker 2008). Thus, we should eliminate the status quo. By contrast, according to others, equality demands that we maintain the status quo. ${ }^{20} \mathrm{I}$ accept the latter position for the following reasons.

The view that public funding for IVF would promote equality presumes exactly what I think needs to be questioned in the debate about such funding: that procreation has a high level of importance. Notice that without such a presumption, advocates of the view must accept that the state should remedy inequalities in areas that have relatively little importance. A stark example is an inequality in the ability to sail. The mere fact that only some people can go sailing does not justify public funding for sailing programs. Why not? Because sailing, or having the ability to sail, is simply not important. Surely, people who argue on grounds of equality that the government should fund IVF would agree with this claim. But then it follows that they must accept that, unlike sailing, procreation is important, indeed important enough to fund IVF (despite the nature of IVF and the availability of such alternatives to it as adoption). 
The question then becomes whether the above presumption about procreation is justified. Our earlier discussion about different people's reactions to their fertility or infertility suggests that many people would reject this presumption. Many philosophers, including me, would also reject it. Some of these philosophers accept that parenting is very important for many people (although not for everyone); however, according to them, the goods of parenting do not require procreation (e.g., Brighouse and Swift 2006; Brighouse and Swift 2014; De Wispelaere and Weinstock 2014; Overall 2014). One can have these goods through adoption, for example. Others assume that even parenting, or being able to become a parent, is not essential to living well (i.e., for anyone), and that it would be better for the planet and people currently living on it if we were to procreate less (e.g., MacIver 2015; Benatar 2015). I'm inclined to accept the first position, but am also persuaded of some aspects of the second.

According to both of the above positions in the philosophical literature on parenting, having biological children, or having the capacity to do so, is a mere preference rather than a basic need or an objective interest (i.e., an interest that one must satisfy in order to live a good life). Using this understanding of procreation, we can see why equality would demand that the government not subsidize people's attempts to procreate through IVF, since a kind of inequality occurs when the government supports the fulfillment of some preferences (e.g., to have biological children) but not others (e.g., to travel the world). Some people get special treatment that they do not deserve, because what is at stake for them again is the satisfaction of a mere preference. And though we should perhaps tolerate such undeserved treatment when it results in minor inequalities - for example, the inequality that might occur when space in a public park is devoted to skateboarders rather than to tennis players-we should not tolerate it when it results in major inequalities. Yet, inequalities of the latter sort would almost certainly occur if IVF were 
publicly funded, because some people would be spared having to pay thousands of dollars to fulfill a preference they have for biological children. It follows, on grounds of equality, that IVF should not be designated a medically necessary service so that it receives public funding.

Some might object to the claim that public funding for IVF would result in major inequalities by asserting that, so long as the funding goes only to IVF with single embryo transfer, it would result in a net cost savings to the government (i.e., on the grounds that it would diminish the costs associated with treatment induced multiple births; Report 111-14). Thus, it isn't as though ultimately the government would be spending a lot of money to satisfy some people's preference for IVF. To respond, even if that were true, however, the funding would still create substantial inequality. Those of us who think that parenthood is an important good should be concerned especially with the inequality that such a system would create between people who choose IVF and those who choose private (domestic or intercountry) adoption. Both servicesIVF and private adoption — cost individuals thousands of dollars (which isn't usually the case with public domestic adoption, in Canada at least; see below). But if IVF were publicly funded, it would cost individuals nothing — or relatively little, depending on how much it is fundedwhile people who prefer private adoption would still pay out of pocket. Such inequality is intolerable, in my opinion.

In short, equality demands that the government support, not the preference that many people have for a particular kind of parenting (i.e., biological parenting), but either all kinds of parenting or none of them. Public funding for IVF would do the former alone, and so would not promote equality. In fact, it would do the very opposite.

\section{Fairness}


The above discussion about equality suggests that it would be unfair of the government to subsidize a particular way of becoming a parent to the exclusion of others and also perhaps of the worthy projects of people who prefer not to have children. ${ }^{21}$ However, some might complain that the government already engages in such unfair behavior when it funds public (domestic) adoptions. The Ontario government, for example, offers to pay all of the expenses associated with a public adoption (although some people pay themselves for private home studies and privately run, government mandated parenting classes when public versions of these services have long waiting lists). Indeed, if the government were to recognize IVF as a medically necessary service, would it not simply level the playing field between assisted reproduction and adoption — at least of the public domestic variety—rather than give the advantage to reproduction? This comparison between assisted reproduction and public domestic adoption is not a good one, however, because it ignores the prior obligation of the government to children who are wards of the state. The government has a special obligation toward these childrennormally, an obligation to find them "forever families"- that it would abandon if it failed to support public adoption. Moreover, because of this obligation, it can legitimately favor this form of family-making over other forms or over a commitment to being child-free.

A better comparison would be between assisted reproduction and private adoption. In neither case does the above sort of obligation exist for the government. Hence, if our concern is with fairness, we should consider whether funding IVF would be fair given the support the government currently gives to these adoptions.

Some jurisdictions provide tax credits to people who adopt children (privately or otherwise) ${ }^{22}$ Canada and Ontario are among them. Currently, people in Ontario who succeed with an adoption are eligible for a small provincial tax credit and a larger federal tax credit. In 
2016 , the provincial credit was 5.05 percent of up to $\$ 12,033$ CAD in eligible expenses for a completed adoption, which amounts to at most $\$ 608$ (Canada Revenue Agency 2016a). The federal credit, in the same year, was 15 percent of up to $\$ 15,255$ CAD in eligible expenses, which is, at most, $\$ 2,288 \mathrm{CAD}$ (Canada Revenue Agency 2016b). These numbers show that people get very little financial support for private adoptions from the Ontario government, although they qualify for more substantial support from the federal government. Still, the maximum subsidy available to them, in 2016 , was only $\$ 2,896 \mathrm{CAD}$, which is a fraction of what most private adoptions cost. (It would not even cover the cost of a private home study and privately run, government mandated parenting classes.) Moreover, those who pay in full for a private adoption but never succeed in adopting a child privately do not qualify for any subsidy. I personally know a number of people who fall into this category.

Now, compare the current subsidies for private adoptions with subsidies proposed for IVF in Ontario. The Report (2009) recommended that the Ontario government fund up to three cycles of IVF, along with various other services (118). ${ }^{23}$ The government later announced that it would fund one cycle, with single embryo transfer, starting in 2015 (and it made good on this promise in December of that year; Ontario Ministry of Health and Long-Term Care 2014; 2015). Even funding only one cycle, however, would save people who do IVF much more than $\$ 2,896$ $\mathrm{CAD}$, and decidedly more than $\$ 608 \mathrm{CAD}$, given that people pay roughly $\$ 6,000 \mathrm{CAD}$ for one cycle now (Report 2009, 110). Also, the funding would go to everyone who attempts one cycle, regardless of whether they get pregnant in the end (of course), whereas adoption subsidies are again available only to people who succeed in adopting a child.

To return to the question we started with: would funding IVF be fair given the support the government now provides for private adoptions? The answer with respect to Ontario is clearly 
no - and it will depend for other jurisdictions, of course, on whether or to what extent the government helps to defray the cost of private adoptions. Publicly funding just one cycle of IVF in Ontario would make the playing field distinctly unlevel for people in Ontario who do private adoptions compared to people who pursue IVF. It would also arguably be unfair to people whose personal goals do not include becoming a parent and who do not receive government support for pursuing these goals, especially those comparable in worth to parenthood. Such concerns about fairness provide a second reason against classifying IVF as a medically necessary service and publicly funding it on these grounds. Granted, this reason exists only so long as the government refuses to provide comparable subsidies for private adoptions and for similarly worthy pursuits. ${ }^{24}$

\section{Harm}

A third reason has to do with harm: valuing procreation as much as the government would have to do to insist that IVF is medically necessary would create what philosophers call expressive harm. ${ }^{25}$ In particular, the claim that IVF is necessary would express to people who do not try, or who stop trying, to remedy infertility through IVF that they have resigned themselves to a stunted life: one of poor health and limited contentment. Included among these people are those who adopt or foster children, and also those who choose not to become parents. The implications for adoptive families in Ontario are particularly significant given our government's mandate for the Expert Panel (2009) to work to make Ontario a "family-friendly province" by improving both its fertility and adoptive services (2). Ontario would, in my opinion, not be friendly to adoptive families if it determined that IVF was medically necessary. It would signal that adoption is an inferior way of forming a family with children, which would be hurtful to many people, including some adoptive parents who love their children and find adoption very fulfilling, to children who are adopted and love their parents, and also to children who are 
waiting or hoping to be adopted. The message to the children would be that they could never fill the psychological hole that is left behind by an unfulfilled desire to be a biological parent. Their families, if they ever get families, will always be second best to biological families. ${ }^{26}$

The outcome just described is made more likely by the fact that Canadian society, like many other societies, does not always treat adoptive families equally to biological ones. Such background conditions will negatively influence the social meaning that the claim that IVF is medically necessary will have. There are norms lingering in our society that philosophers call bionormative, which suggest that families ought to be biological because real or natural families are this way (Haslanger 2009; Witt 2014; Baylis and McLeod 2014). As a result, people sometimes ask adopted children whether they know their "real" parents or whether their sibling is their "real" sibling. People also sometimes refer to families or to what families are like (i.e., "real" ones) without including adoptive families. (The part of the Report [2009] on assisted reproduction does this when it refers to people needing assisted reproduction to build their families [e.g., 109, 114], by which it must mean biological families.) Because many societies are at least somewhat bionormative, they stigmatize adopted children and their parents (Haslanger 2009). This stigma would contribute to the negative implications of the government insisting that IVF is medically necessary. ${ }^{27}$

One might object to the point about expressive harm by stating that negative messages for adoptive families are justified if the alternative of refusing to fund IVF on grounds of medical necessity is that many people cannot lead good lives. These are people who strongly desire to have biological children and who are candidates for IVF but who cannot afford to pay for it themselves. Surely, we can expect some people to have to deal with some negativity towards their families for the sake of others whose lives would be seriously marred if they did not have 
biological children. In response, let me say three things: (1) it is doubtful that we should expect this much of some people, given the damage that these social messages can cause, particularly among children (Haslanger 2009, Leon 2002); (2) we should not have to expect this of anyone in an egalitarian society (i.e., that they tolerate negative messages from the government about their families even though their family members' needs are met); and lastly (3) we should not always accept the claims people make that biological reproduction is essential to them leading good lives. To expand briefly on this last point: people's reasons can be discriminatory—for example, sexist (women are not real women unless they bear children) — or simply based on misinformation. For instance, it is common for people to believe that, on the whole, adoptive families do not function well or that the majority of adopted children have behavioral problems (Wegar 2000). Yet, the sociological evidence on adoption actually confirms the opposite (Blake et al. 2014). In summary, there are good reasons not to allow the fallout that public funding for IVF would have for adoptive families so that other people can realize their pronatalist vision of a good life (i.e., a vision that necessarily includes bearing children).

Before concluding this section, let me be clear that the above concern about expressive harm applies to funding for IVF grounded in medical necessity. (By contrast, notice that the concerns about equality and fairness apply to any funding, regardless of what grounds it.) If the government could provide some subsidy to IVF patients-in the form of a tax credit, for example — but do so on grounds other than medical necessity, it might avoid causing expressive harm. Without endorsing such a subsidy, let me say two things about it: (1) it may be appropriate given the anguish many people admittedly feel when IVF provides their only hope of having biological children; and (2) it should definitely not be greater than what the government offers to 
people who choose adoption (McLeod 2015) or engage in similarly worthy pursuits, that is, for reasons having to do with equality and fairness.

The main purpose of this section has been twofold: first, to show that to deem IVF medically necessary, the government would have to value procreation a great deal, more than it values other methods of building families with children or being child-free, and second, to explain why, in my view, it should not value procreation this much. The main reasons I gave in favor of the second point had to do with equality, fairness, and (expressive) harm. I have also suggested that the presumed superiority of procreation over adoption may not fit with the facts about adoption, ${ }^{28}$ which indicate that most adoptive families function well. Let me add that I also doubt that such a claim coheres with my government's values concerning families, given the desire it showed in convening the Expert Panel of improving both adoption and assisted reproductive services in Ontario.

\section{Conclusion}

The Report (2009) asserts that Ontario wants to be a place that values all families with children. Presumably, many governments like Ontario's desire the same thing. However, such a desire is not compatible with them deeming IVF to be a medically necessary service. Classifying IVF in this way is impossible without suggesting that procreation is so important that some people (namely women) should be willing to sacrifice much of their time, their physical comfort, and possibly their emotional well-being to be able to conceive and bear children. Stating that such actions are necessary for many infertile people also ignores adoption as an option or, at the very least, implies that it should be everyone's second choice. In addition, it suggests that infertile people who decide against assisted reproduction and in favor of a life without children 
will never achieve the level of well-being possible with parenting a child. A government that conveys such messages to the public is friendly only to certain families with children, and at the expense of people who choose not to have children.

\section{Acknowledgements}

For his expert research assistance on this paper, I would like to thank Reuven Brandt. I would also like to thank Reuven, Andrew Botterell, and an anonymous $I J F A B$ reviewer for their helpful comments on an earlier version (or versions) of the paper.

\section{Notes}

1. The government decided, in the end, to fund "one IVF cycle per eligible patient per lifetime" though not using OHIP (Ontario Ministry of Health and Long-Term Care [2015]; see also Martin Regg Cohn [2015a]). My commentary on this decision appears in McLeod (2015).

2. In the academic debate on this topic, some say that IVF is indeed medically necessary or fulfills a medical need (Johnston and Gusmano 2013; McMillan 2001; McMillan 2003), while others are committed to the opposite view (De Wispelaere and Weinstock 2014; Rulli 2014; Baylis 2013; Bartholet 1993; Bartholet 1995). But what is more, most bioethicists and philosophers have been silent on whether IVF should be deemed a medically necessary service.

3. Assuming that to procreate is to produce genetically related children, not all IVF involves procreation. When people do IVF with donor gametes, they do not procreate. I focus on IVF that does not use donor gametes, because it is the main target of public funding campaigns for IVF in Canada. 
4. Despite the role that medical necessity plays in federal legislation about health care in Canada, no formal definition of the term appears in federal law or policy (Charles et al. 1997). But we need at least a working definition to be able to decide whether IVF is medically necessary. I use the common sense understanding just described, which is admittedly vague because it includes "health," a term whose meaning is contested. Below, however, I provide some insight into how to interpret this concept.

5. I am assuming, more explicitly, that health is subjectively valuable in the sense not simply that we value what we judge to be healthy but that our values influence those judgments in the first place. By contrast, some philosophers argue that health is objectively (or inherently) valuable. On this view, health is valuable regardless of whether we view it that way. Although I find this alternative view about health compelling, my understanding of medical necessity relies only on the weaker view that health has subjective value.

6. To be more exact, Boorse (1997) defined disease in his later work as a dysfunction that is typical not of a whole species but of a reference class, which is smaller than a species and may include an age group (Ereshefsky 2009, 222). Boorse recognized, for instance, that "normal reproductive capacity varies among different age classes of humans" (222). On his account, infertility is a disease only for people who are members of certain age groups.

7. In the clinical context, infertility is given the following "time-based definition": the inability to conceive after twelve months of regular unprotected sexual intercourse (Mladovsky and Sorenson 2010, 117).

8. I know of no bioethicist or philosopher who defends this conclusion about medical necessity; however, I think discussing it is important because those who accept Boorse's theory of health would be drawn to it. As I have said, this theory is prominent, especially in medicine. 
9. One might object that nondiseased people could receive treatment on grounds other than medical necessity and have this treatment funded, which, in Ontario, would have to occur through tax credits. Whether such a system — where the type of funding and the reasons for it differ between different groups — would be fair, however, would depend on different factors, including whether it would be unduly burdensome financially for one group (i.e., the one that has to pay out of pocket initially for treatment).

10. As this discussion suggests, labeling something a "disease" does not settle the question of whether treatment for it is medically necessary. For example, some will simply point to the World Health Organization's (2016) designation of infertility as a disease to show that IVF is medically necessary. But such an argument will be unsuccessful because, even if WHO's position were correct, IVF still might not be medically necessary.

11. Sometimes, these disagreements focus not on biological or medical facts but on what has value (Ereshefsky 2009, 222). The debate over whether infertility is a disease is a case in point. Participants generally disagree not about the biological causes of infertility, but on how valuable procreation is. The point is that, to be able to explain such disagreements, one has to recognize the role values play in determining who is healthy or diseased.

12. This means that even he would not accept the conception of medical necessity used in the above argument. He would not agree that judgments about what is medically necessary can be value neutral.

13. Included in this group are people who desperately want to have children, but are not concerned with whether the children they have are biologically related to them. Parenthood is more important to these people than procreation. As a result, they may turn immediately to adoption, rather than try assisted reproduction, upon receiving a diagnosis of infertility. 
14. The Canadian Fertility and Andrology Society (2014) reported that, in 2013, the live birth rate in Canada per fresh embryo transfer cycle was 41 percent for women under thirty-five years of age, 30 percent for women ages thirty-five to thirty-nine, and 14 percent for women ages forty and over. For frozen embryo transfer cycles, the numbers were 31 percent, 24 percent, and 15 percent, respectively.

15. For example, patients might get the good news one day that the physicians were able to extract ten eggs but then get the bad news the next day that only four of the eggs were mature enough to be fertilized. They then find out that three of the four fertilize, but only one of the resulting embryos is actually worth implanting.

16. More specifically (and to distinguish adoptive parenting from foster parenting), one is able to develop a permanent relationship with a child as his or her parent. On whether the goal of having such a relationship is the most important aspect of procreating, we would surely balk if a man were to say that his main aim in procreating was to spread his seed, or a woman were to say that her main goal was to experience pregnancy (O’Neill 1979; Botterell and McLeod 2015).

17. One need not assume, however, that procreation is worth this much for everyone; one could accept both that IVF is medically necessary and that it is reasonable for some infertile people to refuse it on the grounds that the trade-offs they would have to make are too high for them. At the same time though one would be committed to the view that these people's lives are deficient, because they have not been able to procreate.

18. I personally found adoption easier for a number of reasons, one of which is because, with IVF, the blood tests, ultrasounds, and hormone injections, and so on are a constant reminder (particularly for the woman undergoing them) that one is struggling to have a child. By contrast, with adoption, once the home study is in, one can become immersed in other things while 
waiting for a referral for a child. One can focus less on becoming a mother, which is important when one is having difficulty doing so.

19. My work as chair of the board for Adopt4Life (n.d.), Ontario’s Adoptive Parent Association, focuses on making the necessary changes to adoption systems in this province.

20. This was the view of the majority in the audiences at two panels I organized at meetings of the Canadian Philosophical Association (at the University of Victoria in 2013 and at Brock University in 2014). The first panel concerned whether IVF should be publicly funded, while the second focused on Family-Making: Contemporary Ethical Challenges (Baylis and McLeod 2014), which covers the topic of IVF funding.

21. I assume that concerns about equality and fairness are tightly linked in this context. Thus, government measures that make it financially more difficult for people to adopt children than to pursue IVF would result not only in inequality, but also unfairness.

22. There is such a tax credit in the United States. See, for example Independent Adoption Center (n.d.).

23. The other services include embryo freezing and frozen embryo transfer. In addition, the Expert Panel (2009) recommended that the government "introduce a 50\% refundable tax credit with a ceiling of $\$ 20,000 \ldots$ to help offset the costs of fertility medications" (122; emphasis added). By contrast, it said that the provincial adoption tax credit should change only so that the ceiling for allowable expenses increases to $\$ 30,000$ CAD (82). The credit would still be nonrefundable and given at the provincial tax rate. Such a system of provincial funding for IVF and adoption would be grossly unfair, in my opinion, to people who adopt children.

24. I assume here and elsewhere in this paper that private adoptions, including many intercountry adoptions, are worth doing. But some will object to this assumption concerning 
intercountry adoptions. In the words of one of the anonymous reviewers of this paper, this form of adoption "has to be understood as part of a global economy, where the demand for children leads to a supply of children." This view, which describes one pole in the highly polarized debate about intercountry adoption, is extreme in my opinion (as is the opposite pole, according to which intercountry adoption is absolutely wonderful and should be seriously expanded). I cannot defend my position here on intercountry adoption, but see Elizabeth Bartholet and David Smolin (2012) to get some sense of the debate.

25. Jurgen De Wispelaere and Daniel Weinstock (2014) worry about this outcome when discussing state policies that embrace the view that one method of becoming a parent is superior to all others.

26. To be clear, my point is not that anyone would intend to send these messages. We cannot always control what messages people receive from our actions, usually because of social norms that give meaning to them that may conflict with our intentions. On norms that are relevant to understanding the social meaning of claims that IVF is medically necessary, see the next paragraph in the body of this paper.

27. A negative implication other than expressive harm might be that people see adoption as a less and less viable alternative to IVF, that is, if they are told that IVF is indeed medically necessary. They might, in fact, ignore this option altogether.

28. I have not gone so far as to claim that this allegation of superiority is false, although I do believe it is. See Christine Overall (2014) and Elizabeth Brake and Joseph Millum (2012) (in particular, their section on the morality of procreation).

\section{References}


Adopt4Life. n.d. http://www.adopt4life.com

Bartholet, Elizabeth. 1993. Family Bonds: Adoption, Infertility, and the New World of Child Protection. Boston, MA: Beacon Press.

Bartholet, Elizabeth. 1995. "Beyond Biology: The Politics of Adoption \& Reproduction.” Duke Journal of Gender Law \& Policy 2 (1): 5-13.

Bartholet, Elizabeth, and David Smolin. 2012. “The Debate.” In Intercountry Adoption: Policies, Practices, and Outcomes, ed. Judith L. Gibbons and Karen Smith Rotabi, 233-54. Surrey, UK: Ashgate.

Baylis, Françoise. 2013. “Who’s Paying for IVF?” The Mark, February 27. http://www.dal.ca/content/dam/dalhousie/pdf/sites/noveltechethics/498.pdf

Baylis, Françoise, and Carolyn McLeod, eds. 2014. Family-Making: Contemporary Ethical Challenges. Oxford: Oxford University Press.

Benatar, David. 2015. "The Misanthropic Argument for Anti-natalism.” In Permissible Progeny: The Morality of Procreation and Parenting, ed. Sarah Hannan, Samantha Brennan, and Richard Vernon, 34-64. New York: Oxford University Press.

Blake, Lucy, Martin Richards, and Susan Golombok. 2014. “The Families of Adoption and Assisted Reproduction.” In Family-Making: Contemporary Ethical Challenges, ed. Françoise Baylis and Carolyn McLeod, 64-85. Oxford: Oxford University Press.

Boorse, Christopher. 1975. "On the Distinction between Disease and Illness." Philosophy \& Public Affairs 5 (1): 49-68.

Botterell, Andrew, and Carolyn McLeod. 2015. "Can a Right to Reproduce Justify the Status Quo on Parental Licensing?" In Permissible Progeny: The Morality of Procreation and 
Parenting, ed. Sarah Hannan, Samantha Brennan, and Richard Vernon, 184-207. New York: Oxford University Press.

Brake, Elizabeth, and Joseph Millum. 2012. "Parenthood and Procreation." Stanford Encyclopedia of Philosophy (online), ed. Edward N. Zalta. http://plato.stanford.edu/entries/parenthood/

Brighouse, Harry, and Adam Swift. 2006. "Parents' Rights and the Value of the Family." Ethics 117 (1): 80-108.

Brighouse, Harry, and Adam Swift. 2014. “The Goods of Parenting.” In Family-Making: Contemporary Ethical Challenges, ed. Françoise Baylis and Carolyn McLeod. 11-28. Oxford: Oxford University Press.

Canada Health Act. 1985. R.S.C., c. C-6.

Canada Revenue Agency. 2016a. "Line 5833-Adoption Expenses." http://www.craarc.gc.ca/E/pub/tg/5006-pc/5006-pc-15e.html\#P66 5698

Canada Revenue Agency. 2016b. "Line 13-Adoption Expenses." http://www.craarc.gc.ca/tx/ndvdls/tpcs/ncm-tx/rtrn/cmpltng/ddetns/lns300-350/313/menu-eng.html

Canadian Fertility and Andrology Society. 2014. "Position Statement: The Case for Public Funding of In Vitro Fertilization (IVF) with Elective Single Embryo Transfer (eSET) in Canada." https://cfas.ca/wpcontent/uploads/2014/11/Position_Statement_Public_Funding_of_IVF1.pdf

Charles, Cathy, Jonathan Lomas, and Mita Giacomini. 1997. "Medical Necessity in Canadian Health Policy: Four Meanings and ... a Funeral?” The Milbank Quarterly 75 (3): 365-94. 
Chen, Ting-Hsiu, Sheng-Ping Chang, Chia-Fen Tsai, and Kai- Dih Juang. 2004. "Prevalence of Depressive and Anxiety Disorders in an Assisted Reproductive Technique Clinic." Human Reproduction 19 (10): 2313-18.

Cohn, Martin Regg. 2015a. "Liberals Trying to Have It Both Ways on IVF funding.” The Toronto Star, October 15. http://www.thestar.com/news/queenspark/2015/10/15/liberalstrying-to-have-it-both-ways-on-ivf-funding-cohn.html

Cohn, Martin Regg. 2015b. "Premier Ponders Blowing Up Our CAS Mess.” The Toronto Star, December 22. http://www.thestar.com/news/canada/2015/12/22/premier-pondersblowing-up-our-cas-mess-cohn.html

Cousineau, Tara M., and Alice D. Domar. 2007. "Psychological Impact of Infertility.” Best Practice \& Research Clinical Obstetrics and Gynaecology 21 (2): 293-308.

Daniels, Norman. 1985. Just Health Care. Cambridge, UK: Cambridge University Press.

De Wispelaere, Jurgen, and Daniel Weinstock. 2014. "State Regulation and Assisted Reproduction: Balancing the Interests of Parents and Children." In Family-Making: Contemporary Ethical Challenges, ed. Françoise Baylis and Carolyn McLeod, 131-50. Oxford: Oxford University Press.

Domar, A. D., P. C. Zuttermeister, and R. Friedman. 1993. “The Psychological Impact of Infertility: A Comparison with Patients with Other Medical Conditions.” Journal of Psychosomatic Obstetrics \& Gynaecology 14: S45-52.

Ereshefsky, Mark. 2009. “Defining 'Health' and 'Disease'," Studies in History and Philosophy of Biological and Biomedical Sciences 40 (3): 221-27. 
Freeman, Ellen W., Andrea S. Boxer, Karl Rickels, Richard Tureck and Luigi Mastrioianni Jr. 1985. "Psychological Evaluation and Support in a Program of In Vitro Fertilization and Embryo Transfer." Fertility \& Sterility 43 (1): 48-53.

Greil, Arthur. 1997. "Infertility and Psychological Distress: A Critical Review of the Literature." Social Science \& Medicine 45 (11): 1679-704.

Hannan, Sarah, Samantha Brennan, and Richard Vernon, eds. 2015. Permissible Progeny: The Morality of Procreation and Parenting. New York: Oxford University Press.

Haslanger, Sally. 2009. "Family, Ancestry and Self: What is the Moral Significance of Biological Ties?” Adoption \& Culture 2 (1): 91-122.

Independent Adoption Center. n.d. "The Adoption Tax Credit in 2015 and 2016." http://www.adoptionhelp.org/adoption-tax-credit

Johnston, Josephine, and Michael K. Gusmano. 2013. "Why We Should All Pay for Fertility Treatment: An Argument from Ethics and Policy.” Hastings Center Report 43 (2): 18-21. Kaposy, Christopher. 2009. "The Public Funding of Abortion in Canada: Going Beyond the Concept of Medical Necessity." Medicine, Health Care, and Philosophy 12 (3): 301-11.

Leon, Irving G. 2002. “Adoption Losses: Naturally Occurring or Socially Constructed?” Child Development 73 (2): 652-63.

MacIver, Cory. 2015. "Procreation or Appropriation?" In Permissible Progeny: The Morality of Procreation and Parenting, ed. Sarah Hannan, Samantha Brennan, and Richard Vernon, 107-28. New York: Oxford University Press.

McLeod, Carolyn. 2015. "Building Families Equitably in Ontario." The Toronto Star, November 1. http://www.thestar.com/opinion/commentary/2015/11/01/building-families-equitablyin-ontario.html 
McLeod, Carolyn, and Andrew Botterell. 2014. “Can Public Funding for IVF Be Justified?” In Due Course: A Canadian Public Affairs Blog. http://induecourse.ca/can-public-fundingof-ivf-be-justified/

McLeod, Carolyn, and Julie Ponesse. 2008. "Infertility and Moral Luck: The Politics of Women Blaming Themselves for Infertility." IJFAB: International Journal of Feminist Approaches to Bioethics 1 (1): 126-44.

McMillan, John. 2001. “Allocating Fertility Services by Medical Need," Human Fertility 4 (1): 11-13.

McMillan, John. 2003. "NICE, the Draft Fertility Guideline and Dodging the Big Question." Journal of Medical Ethics 29: 313-14.

Mladovsky, Philipa, and Corinna Sorenson. 2010. "Public Financing of IVF: A Review of Policy Rationales." Health Care Analysis 18 (2): 113-28.

Nisker, Jeffrey. 2008. “Distributive Justice and Infertility Treatment in Canada.” Journal of Obstetrics and Gynaecology Canada 30 (5): 425-31.

O’Neill, Onora. 1979. “Begetting, Bearing, and Rearing.” In Having Children: Philosophical and Legal Reflections on Parenthood, 25-38, ed. Onora O’Neill and William Ruddick, 25-38. New York: Oxford University Press.

Ontario Ministry of Children and Youth Services. 2009. Expert Panel on Infertility and Adoption. Raising Expectations: Recommendations of the Expert Panel on Infertility and Adoption, August. http://www.children.gov.on.ca/htdocs/English/infertility/index.aspx Ontario Ministry of Health and Long-Term Care. 2014. "Improving Access to Safe Fertility Treatments: Ontario Sharing Cost of IVF to Help People Who Cannot Conceive Children.” News Release, April 10. 
https://news.ontario.ca/mohltc/en/2014/04/improving-access-to-safe-fertilitytreatments.html.

Ontario Ministry of Health and Long-Term Care. 2015. "Improving Access to Fertility Treatments for Ontario Families: Removing Barriers for Ontarians Who Want to Grow Their Families.” News Release, October 1. https://news.ontario.ca/mohltc/en/2015/10/improving-access-to-fertility-treatments-forontario-families-1.html

Overall, Christine. 2014. "What is the Value of Procreation?" In Family-Making: Contemporary Ethical Challenges, ed. Françoise Baylis and Carolyn McLeod. 89-108. Oxford: Oxford University Press.

Rulli, Tina. 2014. “The Unique Value of Adoption.” In Family-Making: Contemporary Ethical Challenges, ed. Françoise Baylis and Carolyn McLeod. 109-28. Oxford: Oxford University Press.

Suthersan, Dharani, Sandra Kennedy, and Michael Chapman. 2011. "Physical Symptoms Throughout IVF Cycles." Human Fertility 14 (2): 122-28.

Uniacke, Susan. 1987. "In Vitro Fertilization and the Right to Reproduce." Bioethics 1 (3): 24154.

Wegar, Katarina. 2000. “Adoption, Family Ideology, and Social Stigma: Bias in Community Attitudes, Adoption Research, and Practice." Family Relations 49 (4): 363-70.

Witt, Charlotte. 2014. "A Critique of the Bionormative Concept of the Family." In FamilyMaking: Contemporary Ethical Challenges, ed. Françoise Baylis and Carolyn McLeod, 49-63. Oxford: Oxford University Press. 
World Health Organization. (2016) "Infertility Definitions and Terminology." http://www.who.int/reproductivehealth/topics/infertility/definitions/en/

\section{Contributor Information}

Carolyn McLeod is a professor of philosophy at Western University in London, Canada.

Her research bridges the areas of reproductive ethics, feminist philosophy, and moral philosophy.

She recently edited Family-Making: Contemporary Ethical Challenges with Françoise Baylis (2014) and is currently completing a monograph, Conscience in Reproductive Health Care (Oxford University Press, forthcoming). 